\title{
sciendo
}

\section{UTERINE CHARACTERISTICS OF PREPUBERTAL GILTS AT FIXED BODY WEIGHT*}

\author{
Hanna Jankowiak», Wojciech Kapelański, Maria Bocian \\ Department of Animal Breeding, UTP University of Science and Technology in Bydgoszcz, 85-084 \\ Bydgoszcz, Poland \\ •Corresponding author: jankowiak@utp.edu.pl
}

\begin{abstract}
Reproduction is one of the most important factors affecting the efficiency of animal production. Within the scope of uterine capacity and other morphometric parameters, the objective of this study was to evaluate the size variability of uterus dissected from prepubertal gilts. The research was conducted on 100 PLW gilts and 100 PL gilts at a pig testing station. After slaughter, the reproductive tract was dissected, and each element was measured and weighed. The obtained results were combined and analyzed in three groups differentiated by uterine capacity: I, II and III. Group I consisted of gilts with a uterine capacity below $115 \mathrm{~cm}^{3}(\mathrm{n}=69)$; group II comprised gilts with a uterine capacity between 115 and $175 \mathrm{~cm}^{3}(\mathrm{n}=85)$; uterine capacity in group III was above $175 \mathrm{~cm}^{3}(\mathrm{n}=46)$. Ontogenesis of the reproductive tract showed great variability with respect to the uterine capacity of gilts of both breeds. Uterine weight with and without ligament was different between the analyzed groups of PLW gilts $(P<0.01)$, and also between the groups of PL gilts $(\mathrm{P}<0.01 ; \mathrm{P}<0.05)$. The uterine horns of the PLW gilts in group I were slightly longer than in the PL gilts $(90.76 \mathrm{~cm}$ vs. $84.20 \mathrm{~cm} ; \mathrm{P}<0.05)$. A slightly higher variability of uterine capacity was observed with respect to the PLW gilts $\left(80.92 \mathrm{~cm}^{3}\right.$ to $\left.243.13 \mathrm{~cm}^{3}\right)$, as compared with the PL gilts $\left(92.61 \mathrm{~cm}^{3}\right.$ to $\left.235.23 \mathrm{~cm}^{3}\right)$. The determined uterine capacity was significantly correlated with all parameters of uterine size $(\mathrm{P}<0.01)$, apart from the length of the uterus and cervix in PLW gilts. The proportion between the uterine weight and the length of its horns, which characterizes the thickness of uterine walls, was significantly correlated with the length of uterine horns only in PL gilts $(r=0.382 * *)$. This study may be used to forecast the potential fertility of related females (littermate gilts and their daughters); it may also be used in sow selection for litter size.
\end{abstract}

Key words: pigs, reproduction, reproductive tract, uterine development

The fertility of sows, as described by the number of piglets per litter, is a trait that is difficult to improve by direct selection and it is also an important component of economic pig production efficiency. Therefore, exploring the new direct and indirect

\footnotetext{
*This study was financed as research project from education funds between 2009-2012.
} 
criteria of selection for increased litter size might be reasonable and necessary (Lents et al., 2014; Freking et al., 2007; 2016). In Polish breeding practice, a representative part of the female pig population is controlled at slaughter testing stations (Różycki and Tyra, 2010). This provides an opportunity to obtain at slaughter the reproductive organs of tested gilts for detailed analysis. Determining at an early age in gilts the development stage of the reproductive tract, in particular the uterine capacity, seems worth doing to forecast the possible fertility of related littermate females when used as replacement gilts. The measurable parameters of the uterus such as its weight, length of horns, length of cervix and physiological capacity may provide the correct placement and easy development of embryos and fetuses. Vallet et al. (2014) indicate that litter size and piglets' body weight at birth are limited by the capacity of the uterus. Uterine capacity has been defined as a combined effect of uterine, placental and embryonic/fetal function. Recent studies by Vallet et al. (2016) illustrate that total uterine length is positively related to piglet birth weight, but not to preweaning growth rate. In turn, in Vallet et al.'s study, uterine length increased by approximately $100 \mathrm{~cm}$ during the gravidity period. Adequate uterine capacity also determines proper development of the placenta (Bartol et al., 1993; Mesa et al., 2003). Placental efficiency is important for the healthy development of newborn piglets due to the transport of nutrients; however, the growth of the fetus is not fully dependent on placental size, especially during early gestation (Vallet et al., 2014). Wright et al. (2016) reported that the growth and expansion of the placenta is necessary to establish space in the uterus for nutrient exchange and vascular development. The results of studies carried out by Wu and Dziuk (1989) as well as Wu et al. (1987) indicate that there is a relation between the morphometric traits of the uterus and embryo/fetus death during pregnancy. Foxcroft et al. $(2006 ; 2009)$ also noted the above and stated that the reasons for embryo death and deterioration of reproduction effects may be related to the insufficient size of the uterus and the inability to deliver nutrients to fetuses due to increased density of fetuses in the uterus. Therefore, studies which pertain to the shaping of morphometric traits of gilts' reproductive tract have also become significant in terms of improvement of production effects (Kapelański et al., 2013 a).

The purpose of this paper was to study and compare the variability of uterine morphometric parameters of sexually immature gilts of two common pig breeds in Poland: the Polish Large White (PLW) and the Polish Landrace (PL). The data will be used in future to forecast the possible fertility of littermate females used as replacement gilts.

\section{Material and methods}

\section{Animals}

The study comprised 200 gilts (100 of each breed) of the two most common breeds in Poland: the Polish Large White (PLW) and the Polish Landrace (PL). Gilts were chosen in a controlled way and were maintained and fed according to norms 
adopted by Polish Slaughter Pig Testing Stations (Polish abbreviation, SKURTCh), according to the methodology elaborated by Różycki and Tyra (2010). When the animals reached a body weight of approximately $100 \mathrm{~kg}$, they were slaughtered, and their complete reproductive tracts were extracted for assessment. The experimental procedures were approved by the Local Ethics Committee, No. 21/2008.

After dissection of the reproductive tract, the weight of the uterus with and without the broad ligament was determined. Moreover, measurements of the length of the uterus, cervix and uterine horns (right and left) were taken; volumetric capacity of the uterus was measured by filling it with physiological saline solution which was measured according to the methodology described by Kapelański et al. (2013 b). The proportion between the weight of the uterus without the broad ligament and the length of its horns $(\mathrm{g} / \mathrm{cm})$ was calculated; this roughly characterizes the thickness of the uterine walls.

\section{Statistical analysis}

The data were analyzed separately for each of the two breeds and were statistically compared between them. In respect to uterine capacity, all gilts were assigned to three groups according to internal volume. Group I consisted of gilts with a uterine capacity below $115 \mathrm{~cm}^{3}(\mathrm{n}=69)$; group II comprised gilts with a uterine capacity of $115 \mathrm{~cm}^{3}$ to $175 \mathrm{~cm}^{3}(\mathrm{n}=85)$; group III consisted of gilts with a uterine capacity above $175 \mathrm{~cm}^{3}(\mathrm{n}=46)$.

The results were analyzed statistically. Data were given as the arithmetic means \pm standard deviations. To estimate the variability and reciprocal connections between the morphometric parameters of the reproductive organs of PLW and PL gilts, a twofactor analysis of variance was conducted according to the model:

$$
y_{i j k}=\mu+m_{i}+w_{j}+e_{i j k}
$$

where:

$y_{i j k}-$ trait measured on $i j k$-th animal,

$\mu$ - overall mean,

$m_{i}$ - fixed effect of $i$-th uterine capacity $\left(i=\mathrm{I}-<115 \mathrm{~cm}^{3}\right.$, II $-115-175 \mathrm{~cm}^{3}$, III $>175 \mathrm{~cm}^{3}$,

$w_{j}$ - fixed effect of $j$-th breed $(j=$ PLW - Polish Large White, PL - Polish Landrace),

$e_{i j k}$ - random error.

The mean values were compared with the LSD test. Additionally, the linear relationships between the morphometric traits of the reproductive organs of the PLW and PL gilts were calculated. For calculations, the STATISTICA Version 8 software package (StatSoft, 2008) was used. 


\section{Results}

Results of measurements of respective segments of the reproductive tract of gilts are presented in Table 1. These measurements pertained to the weight of the uterus with and without the broad ligament, and the length of the uterus, cervix and uterine horns.

Table 1. Results of morphometric uterine traits assessment in PLW and PL gilts

\begin{tabular}{|c|c|c|c|c|}
\hline \multirow[b]{2}{*}{ Item } & \multirow[b]{2}{*}{ Breed } & \multicolumn{3}{|c|}{ Uterine capacity $\left(\mathrm{cm}^{3}\right)$} \\
\hline & & $\begin{array}{c}\mathrm{I} \\
<115\end{array}$ & $\begin{array}{c}\text { II } \\
115-175\end{array}$ & $\begin{array}{c}\text { III } \\
>175\end{array}$ \\
\hline \multirow[t]{3}{*}{ Number (n) } & PLW & 42 & 42 & 16 \\
\hline & PL & 27 & 43 & 30 \\
\hline & Total & 69 & 85 & 46 \\
\hline \multirow[t]{3}{*}{ Age at slaughter (days) } & PLW & $171.9 \mathrm{x} \pm 18.9$ & $170.2 \pm 16.8$ & $172.6 \pm 20.2$ \\
\hline & PL & $162.6 \mathrm{y} \pm 15.6$ & $165.9 \pm 20.0$ & $169.5 \pm 17.2$ \\
\hline & Average & $168.3 \pm 18.14$ & $168.0 \pm 18.5$ & $170.6 \pm 18.1$ \\
\hline Uterine weight with & PLW & $114.68 \mathrm{~A} \pm 31.56$ & $149.72 \mathrm{~B} \pm 32.20$ & $227.62 \mathrm{C} \pm 82.47$ \\
\hline \multirow[t]{2}{*}{ ligament (g) } & PL & $115.67 \mathrm{Aa} \pm 30.25$ & $147.88 \mathrm{Ab} \pm 38.12$ & $234.08 \mathrm{~B} \pm 79.85$ \\
\hline & Average & $115.07 \mathrm{~A} \pm 30.84$ & $148.79 \mathrm{~B} \pm 35.12$ & $231.84 \mathrm{C} \pm 79.91$ \\
\hline Uterine weight without & PLW & $99.62 \mathrm{~A} \pm 29.22$ & $133.58 \mathrm{~B} \pm 31.16$ & $195.31 \mathrm{C} \pm 78.92$ \\
\hline \multirow[t]{2}{*}{ ligament $(\mathrm{g})$} & PL & $99.58 \mathrm{Aa} \pm 29.03$ & $132.16 \mathrm{Ab} \pm 36.53$ & $210.50 \mathrm{~B} \pm 75.20$ \\
\hline & Average & $99.60 \mathrm{~A} \pm 28.93$ & $132.86 \mathrm{~B} \pm 33.79$ & $205.22 \mathrm{C} \pm 75.99$ \\
\hline \multirow[t]{3}{*}{ Cervical length $(\mathrm{cm})$} & PLW & $12.31 \pm 2.32$ & $12.54 \pm 2.22$ & $13.50 \pm 1.93$ \\
\hline & PL & $11.59 \mathrm{~A} \pm 2.22$ & $12.05 \mathrm{a} \pm 2.13$ & $13.47 \mathrm{Bb} \pm 2.42$ \\
\hline & Average & $12.03 \mathrm{~A} \pm 2.29$ & $12.30 \mathrm{~A} \pm 2.18$ & $13.48 \mathrm{~B} \pm 2.24$ \\
\hline Uterine horns length & PLW & $90.76 \mathrm{Abx} \pm 11.02$ & $100.25 \mathrm{a} \pm 15.71$ & $109.37 \mathrm{Bb} \pm 25.79$ \\
\hline \multirow[t]{2}{*}{$(\mathrm{R}+\mathrm{L})(\mathrm{cm})$} & PL & $84.20 \mathrm{Ay} \pm 12.08$ & $97.36 \mathrm{~B} \pm 11.37$ & $115.95 \mathrm{C} \pm 20.56$ \\
\hline & Average & $88.19 \mathrm{~A} \pm 11.81$ & $98.79 \mathrm{~B} \pm 13.68$ & $113.66 \mathrm{C} \pm 22.45$ \\
\hline Weight/length of horns & PLW & $1.11 \mathrm{Aa} \pm 0.35$ & $1.34 \mathrm{Ab} \pm 0.27$ & $1.87 \mathrm{~B} \pm 0.81$ \\
\hline \multirow[t]{2}{*}{$(\mathrm{g} / \mathrm{cm})$} & PL & $1.18 \mathrm{~A} \pm 0.30$ & $1.36 \mathrm{~A} \pm 0.34$ & $1.89 \mathrm{~B} \pm 0.73$ \\
\hline & Average & $1.13 \mathrm{~A} \pm 0.33$ & $1.35 \mathrm{~B} \pm 0.31$ & $1.89 \mathrm{C} \pm 0.75$ \\
\hline \multirow[t]{3}{*}{ Uterine capacity $\left(\mathrm{cm}^{3}\right)$} & PLW & $80.92 \mathrm{~A} \pm 20.58$ & $142.06 \mathrm{~B} \pm 15.46$ & $243.13 \mathrm{C} \pm 65.48$ \\
\hline & PL & $92.61 \mathrm{~A} \pm 16.36$ & $140.51 \mathrm{~B} \pm 19.03$ & $235.23 \mathrm{C} \pm 64.02$ \\
\hline & Average & $85.49 \mathrm{~A} \pm 19.77$ & $141.27 \mathrm{~B} \pm 17.27$ & $237.98 \mathrm{C} \pm 63.91$ \\
\hline
\end{tabular}

PLW - Polish Large White, PL - Polish Landrace.

$\mathrm{a}, \mathrm{b}$ - values in rows with different letters differ significantly $(\mathrm{P} \leq 0.05)$.

$\mathrm{A}, \mathrm{B}, \mathrm{C}-$ values in rows with different letters differ significantly $(\mathrm{P} \leq 0.01)$.

$\mathrm{x}, \mathrm{y}-$ values in columns with different letters differ significantly $(\mathrm{P} \leq 0.05)$. 


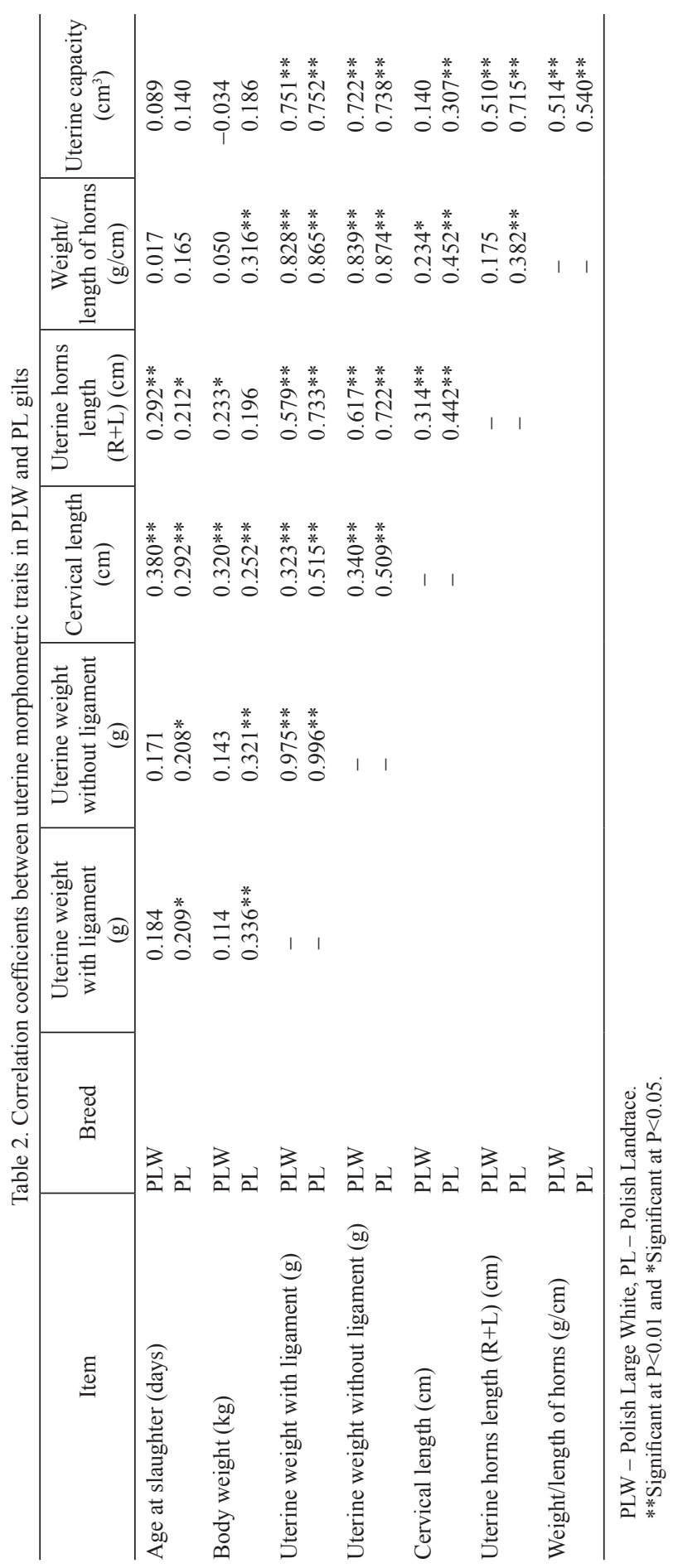


Regardless of the average weight of $100 \mathrm{~kg}$ and the similar age of animals at slaughter, the size of the uterus and its particular elements varied greatly. This suggested that there should be three groups of gilts, I, II and III, which differed in uterine capacity $(\mathrm{P}<0.01)$. The size and proportions of particular segments of the reproductive tract of PLW and PL gilts were very similar within the scope of each evaluated group of gilts (I, II and III). However, in gilt group I, the uterine horns in PLW gilts were slightly longer than in PL gilts $(90.76 \mathrm{~cm}$ vs. $84.20 \mathrm{~cm} ; \mathrm{P}<0.05)$. Also, a slightly higher variability of uterine development in terms of uterine capacity was observed with respect to PLW gilts $\left(80.92 \mathrm{~cm}^{3}\right.$ to $\left.243.13 \mathrm{~cm}^{3}\right)$ as compared with PL gilts $\left(92.61 \mathrm{~cm}^{3}\right.$ to $235.23 \mathrm{~cm}^{3}$ ). The differences between the breeds concerning uterine capacity were not statistically significant.

Correlations between the studied morphometric measurements of the reproductive tract of gilts are presented separately for each breed (Table 2). The highly significant correlation coefficients indicate an intimate relation between uterine capacity, uterine weight, and the length of the horns. Analysis of Table 2 shows that the interrelations between the studied parameters (including body weight) are slightly stronger for PL gilts than PLW gilts. This pertains to a visible dependence between the calculated proportion between the weight of the uterus and the length of its horns $(\mathrm{g} / \mathrm{cm})$, which characterizes the thickness of the uterine walls. While this property was not significantly correlated with the length of uterine horns in PLW gilts, these correlations were statistically highly significant $(\mathrm{P}<0.01)$ in $\mathrm{PL}$ gilts. The uterine capacity significantly correlated with all parameters of uterine size $(\mathrm{P}<0.01)$, apart from the length of the uterus and the cervix in PLW gilts.

\section{Discussion}

Detailed characteristics of uterus size in gilts immediately before reaching sexual maturity constitute unique reference material for evaluating the ontogenesis of the reproductive tract and its variability in two common breeds, i.e. the Large White and the Landrace. A considerable amount of information in the literature indicates that the size of the uterus, in particular its horns, is of paramount importance as far as formation of large litters is concerned (Wu and Dziuk, 1989; 1995; Vallet, 2000; Foxcroft et al., 2009; Lents et al., 2014; Freking et al., 2016).

It will be stressed here that the term 'uterine capacity' as used by many authors (Bazer et al., 1969; Vallet, 2000; Vallet and Freking, 2005; Foxcroft et al., 2009) relates indirectly to the uterus' ability to create the environment needed for implantation of embryos, delivery of nutrients to fetuses, and ample space during pregnancy. Instead, we determined the real internal uterine space with the aid of a method that can measure the volumetric capacity of cavernous organs (Brudnicki et al., 2001; Kapelański et al., 2013 b). Thereby, the term 'uterine capacity' as used by us refers to the internal size of this organ. Therefore, it is possible that our data represents better conditions and greater reproductive potential to increase litter size.

The usefulness of measuring the length of the vagina and cervix when mating sows for the first time has been experimentally proved in terms of fertility forecast- 
ing (Rillo et al., 2001; Dybała et al., 2004). Gilts with longer reproductive tract had larger litters.

As was evaluated by us, the physiological uterine capacity of sexually immature gilts may be used to forecast their potential fertility (Vallet and Freking, 2005). This is indicated by, for instance, the observations of Ji et al. (2005), who demonstrated a linear increase in the weight of the uterus and placenta between the 70th and 112th day of pregnancy. Therefore, one may conclude that a greater uterine capacity at the moment of mating guarantees less frequent embryo and fetus death during pregnancy and, as a consequence, more newborn piglets. Such an opinion is supported by the results of studies carried out by Gama and Johnson (1993), Freking et al. (2007, 2016) and Lents et al. (2014), who demonstrated an advantageous connection between the size of ovulation, uterine capacity, the dimensions of the uterus and the size of a litter. The length of uterine horns determines the possibility of implantation of embryos. In the opinion of Chen and Dziuk (1993) and Wu and Dziuk (1995) pig fetuses require at least $36 \mathrm{~cm}$ initial length of uterus to implant, survive and develop fully during gestation.

It should be highlighted that measurement of the proportions between the weight of the uterus and the length of its horns is extremely useful as an indicator characterizing the thickness of uterine walls. This indicator was significantly correlated with the length of uterine horns only with respect to PL gilts, which, as compared with PLW gilts, showed greater rugosity and better endometrial perfusion in morphological and histological assessments (Kapelański et al., 2012). An increased proportion between uterine weight and length may suggest a greater capability of the uterus to placenta development and in consequence, an improved communication between fetuses and the intrauterine environment during gestation and their greater survival rate. Insufficient placenta development is one cause of low pig reproduction efficiency (Mesa et al., 2003; Van Rens et al., 2005; Wright et al., 2016). The proportion between the weight of the uterus without the broad ligament and the length of its horns was significantly positively correlated with uterine capacity.

\section{Conclusion}

Our morphometric examinations of the reproductive tract of gilts which have not reached sexual maturity provide an abundance of information about the development of the organ and formation of mutual anatomic proportions. They can also be used, presumably, to forecast the potential fertility of related females (littermate gilts and their daughters), or to facilitate directed sow selection for litter size.

\section{References}

B a r to 1 F.F., Wil e y A.A., S pen ce r T.E, Valle t J.L., Chris t e n s e n R.K. (1993). Early uterine development in pigs. J. Reprod. Fertil., Suppl. 48: 99-116.

B a zer F.W., C law s on A.J., R ob is on O.W., Ulberg L.C. (1969). Uterine capacity in gilts. J. Reprod. Fertil., 18: 121-124. 
Brudnicki W., Skoczylas B., Jabłoński R. (2001). Metrical features of some parts of the alimentary canal and liver in raccoon dog (Nyctereutes procyonoides gray), EJPAU 4 (1), \#01, available online: http://www.ejpau.media.pl/volume4/issue1/veterinary/art-01.html.

C h e n Z.Y., D z i u k P.J. (1993). Influence of initial length of uterus per embryo and gestation stage on prenatal survival, development, and sex ratio in the pig. J. Anim. Sci., 71: 1895-1901.

D ybała J., Kapelański W., Ka pelańska J., Wiśniewsk a J. (2004). Gilt fertility in relation to vagina-cervix length. Ann. Anim. Sci., Suppl. 2: 17-20.

Foxcroft G.R., Dixin W.T., Novak S., Putman C.T., Town S.C., Vinsky M.D. (2006). The biological basis for prenatal programming of postnatal performance in pigs. J. Anim. Sci., 84: Suppl. E105-112.

Fox croft G.R., Dix on W.T., D y ck M.K., Novak S., Harding J.C.S., A l me id a F.C.R.L. (2009). Prenatal programming of postnatal development in the pig. In: Control of pig reproduction VIII, Rodriguez-Martinez H., Vallet J.L., Ziecik A.J. (eds). Nottingham University Press, UK, pp. 213-233.

Fre k ing B.A., L e y m a s ter K.A., Vallet J.L., Chris te n s on R.K. (2007). Number of fetuses and conceptus growth throughout gestation in lines of pigs selected for ovulation rate or uterine capacity. J. Anim. Sci., 85: 2093-2103.

Freking B.A., Le nts C.A., Vallet J.L. (2016). Selection for uterine capacity improves lifetime productivity of sows. Anim. Reprod. Sci., 167: 16-21.

G a m a L.L., J o h n s o n R.K. (1993). Changes in ovulation rate, uterine capacity, uterine dimensions, and parity effects with selection for litter size in swine. J. Anim. Sci., 71: 608-617.

J i F., W u G., B l an t o n J.R., K i m S.W. (2005). Changes in weight and composition in various tissues of pregnant gilts and their nutritional implications. J. Anim. Sci., 83: 366-375.

Ka pelański W., Andron ow ska A., Z ię c ik A.J., B oc ian M., D y bała J. (2012). Comparison of sexual maturation and morphological development of the reproductive tract in Polish Large White (PLW) and Polish Landrace (PL) gilts. Proc. 17th International Congress on Biotechnology of Animal Reproduction (ICBAR), Leipzig, Germany.

Ka pelański W., J ankowiak H., B ocian M., Grajewska S., Dybała J., Cebulska A. (2013 a). The effect of the growth rate and meatiness of young gilts during rearing on the growth and development of the reproductive system. Acta Vet. Brno, 82: 19-24.

Kapelański W., Jankowiak H., Bocian M., Grajewska S., Dybała J., Żmudzińs k a A. (2013 b). Morphometric characteristics of the reproductive system in Polish Large White and Polish Landrace gilts at $100 \mathrm{~kg}$ body weight. Ann. Anim. Sci., 13: 45-53.

L e n ts C.A., Cushman R.A., F reking B.A. (2014). Measures of the ovaries and uterus during development of gilts selected for differences in uterine capacity. J. Anim. Sci., 92: 2433-2439.

Mes a H., S a franski T.J., J o hns on R.K., L e mbers on W.R. (2003). Correlated response in placenta efficiency in swine selected for an index of components of litter size. J. Anim. Sci., 81: 74-79.

Rillo M.S., de Alba Romero C., Romero Rodriquez A., Cidoncha F., Zięcik A.J. (2001). Litter size and vagina-cervix catheter penetration length in gilts. Reprod. Domest. Anim., 36: $297-300$.

Róży c k i M., Ty r a M. (2010). Methodology for tested fattening and slaughter value at Pig Testing Station (SKURTCh) (in Polish). IZ PIB Kraków, 28: 93-117.

Valle t J.L. (2000). Fetal erythropoiesis and other factors which influence uterine capacity in swine. J. Appl. Anim. Res., 17: 1-26.

Vallet J.L., Freking B.A. (2005). Research on uterine capacity and litter size in swine. USDA Agric. Research Service (140 KB pdf).

Vallet J.L., Mc Ne el A.K., Miles J.R., Freking B.A. (2014). Placental accommodations for transport and metabolism during intra-uterine crowding in pigs. J. Anim. Sci. Biotechnol., 5: 55, doi:10.1186/2049-1891-5-55.

Vallet J.L., Calderón-Díaz J.A., Stalder K.J., Phillips C., Cushman R.A., Mile s J.R., Rempel L.A., Rohrer G.A., Lents C.A., Freking B.A., Nonneman D.J. (2016). Litter-of-origin trait effects on gilt development. J. Anim. Sci., 94, doi:10.2527/jas2015-9644.

Van Rens B.T.T.M., De Koning G., B ergsma R., Van der Lende T. (2005). Preweaning piglet mortality in relation to placental efficiency. J. Anim. Sci., 83: 144-151. 
Wrigh t E.C., Mil e s J.R., L e n t s C.A., R e m p e 1 L.A. (2016). Uterine and placenta characteristics during early vascular development in the pig from day 22 to 42 of gestation. Anim. Reprod. Sci., 164: 14-22.

Wu M.C., He n tze 1 M.D., D z i u k P.J. (1987). Relationships between uterine length and number of fetuses and prenatal mortality in pigs. J. Anim. Sci., 65: 762-770.

W u M.C., D z i u k P.J. (1989). Effect of initial length of uterus per embryo on fetal survival and development in the pig. J. Anim. Sci., 67: 1767-1772.

W u M.C., D zi u k P.J. (1995). Relationships of length of uterus in prepubertal pigs and number of corpora lutea and fetuses at 30 days of gestation. Anim. Reprod. Sci., 38: 327-336.

Received: 7 VI 2018

Accepted: 12 XII 2018 